\title{
Stroke topography and outcome in relation to hyperglycaemia and diabetes
}

\author{
L Kiers, S M Davis, R Larkins, J Hopper, B Tress, S C Rossiter, J Carlin, S Ratnaike
}

\begin{abstract}
In a prospective study to analyse stroke topography and outcome in diabetics and to determine the prognostic value of blood glucose and glycosylated haemoglobin estimation, we evaluated 176 patients with acute stroke. The patients were classified into four groups on the basis of history, fasting glucose, and glycosylated haemoglobin: euglycaemic patients with no history of diabetes, stress hyperglycaemia, newly diagnosed diabetics, and known diabetics. A high prevalence of undiagnosed diabetes was shown. No difference was found in the type or site of stroke between the four groups. No difference was found in the site of symptomatic or incidental lesions on computerised axial tomography. Patients with stress hyperglycaemia and known diabetics had more severe strokes. Mortality was higher in patients with stress hyperglycaemia, newly diagnosed diabetics, and the combined diabetes groups. This increased mortality was evident in the hyperglycaemic and diabetic groups, even after excluding patients with cerebral haemorrhage. Stroke severity and mortality also increased independently with blood glucose in the euglycaemic group. We conclude that there is a correlation between admission glucose concentration, diabetes, and poor stroke outcome, which may not be attributed to stroke type or location.
\end{abstract}

Epidemiological and necropsy studies show that diabetic patients have a higher incidence of ischaemic stroke than non-diabetic patients. ${ }^{12}$ In the Framingham study the incidence of thrombotic stroke was 2.5 times higher in diabetic men and 3.6 times higher in diabetic women than in those without diabetes. $^{3}$ Wolf and Kannell reported that even when other risk factors such as hypertension and ischaemic heart disease are taken into account diabetes remains an independent risk factor for stroke. ${ }^{4}$ Previous studies have found a range of prevalence of undiagnosed diabetes in acute stroke populations from $6 \%^{5}$ to $42 \%^{6}$.

The type and topography of diabetes-related cerebral infarction may differ from brain infarcts in non-diabetics. In a necropsy survey Kane and Aronson ${ }^{7}$ found that diabetics had more lacunar lesions when compared with non-diabetics, especially in the distribution of the parasagittal perforating arteries. Peress et $a l^{8}$ also reported a higher occurrence of lacunar infarcts in diabetics compared with non-diabetic patients. In the Harvard cooperative stroke registry, ${ }^{9}$ hypertension and diabetes were present respectively in $75 \%$ and $29 \%$ of lacunar cases and $71 \%$ and $43 \%$ of cases in the South Alabama population study. ${ }^{10}$

Several animal studies of experimental cerebral ischaemia have shown that hyperglycaemia increases the severity of ischaemic brain damage. ${ }^{11-13}$ Pulsinelli et al concluded that hyperglycaemia worsened the outcome of cerebral ischaemia in humans. ${ }^{14}$ Other investigators $^{15-17}$ have also found a worse prognosis after stroke in diabetic patients. Despite these reports the relation between blood glucose, diabetes, and stroke outcome remains unclear. Mohr et $a l,{ }^{18}$ based on data from the NINCDS pilot study, found no evidence supporting an adverse effect of blood glucose on the acute course of stroke, including infarct size, although there was a relation between the admission glucose concentration and mortality. Only one other study ${ }^{19}$ has analysed the relation between blood glucose, diabetes, and stroke type. Woo et al used glycosylated haemoglobin $(\mathrm{HbAlc})$ concentrations to distinguish previously undiagnosed diabetes and stress hyperglycaemia groups and concluded that stress hyperglycaemia, but not diabetes, was associated with an increased mortality.

We studied the prevalence of undiagnosed diabetes mellitus in an acute hospital stroke unit and evaluated the neurological outcome in non-diabetics, diabetics, and patients with stress hyperglycaemia. In view of previous reports of a worse prognosis after stroke in hyperglycaemic and diabetic patients, we also determined whether stroke type or site differed between these groups and had any bearing on clinical outcome.

\section{Subjects and methods}

We prospectively studied 176 sequential patients admitted with acute stroke (excluding subarachnoid haemorrhage) of which 152 patients had CT scan. Stroke was defined as a sudden disturbance of focal neurological function with symptoms lasting more than 24 hours and considered to be due to either cerebral infarction or haemorrhage. ${ }^{20}$ Twenty four of the 176 patients $(14 \%)$ had a history of previous stroke. Venous plasma was taken to measure fasting plasma glucose, glycosylated haemoglobin (HbA1c), cholesterol, triglycerides, packed cell volume, urea, creatinine, and fibrinogen within 24 hours after admission. 
The concentration of $\mathrm{HbAlc}$ reflects the average blood glucose concentration over the preceding 2-3 months.

Quantitative determination of $\mathrm{HbAlc}$, free of labile adducts, was performed by electrophoresis with Corning "Glytrac" reagents. Patients were divided into four groups: euglycaemic patients with no history of diabetes (fasting venous plasma glucose $<7.8 \mathrm{mmol} / \mathrm{l}$ ), including euglycaemic patients with normal HbAlc concentration ( $<8.0 \%$ ) and euglycaemic patients with a marginally elevated HbAlc (> 8.0\%); patients with stress hyperglycaemia (no history of diabetes, glucose $>$ $7.8 \mathrm{mmol} / \mathrm{l}$, HbAlc $<8.0 \%$ ); newly diagnosed diabetics (no history of diabetes, glucose $>7.8 \mathrm{mmol} / \mathrm{h}, \mathrm{HbAlc}>8.0 \%$ ); and known diabetics. Diagnosis of diabetes mellitus was based on WHO criteria ${ }^{21}$ for fasting glucose. Patients continued taking any drugs after admission but no patient was treated with corticosteroids.

CT was performed in 152 of the 176 patients with a GE 9800 scanner, with $10 \mathrm{~mm}$ contiguous slices. The mean (SD) time from the onset of symptoms to CT scan was 3.0 (3.0) days. Patients with stress hyperglycaemia (1.0 (1.5) days) and known diabetics (1.9 (1.8) days) had significantly earlier scans than the euglycaemic, non-diabetic patients (3.2 (2.9) days, $\mathrm{p}<0.01)$. There was no significant difference in the time from onset to CT scan between the euglycaemic, non-diabetic patients, and newly diagnosed diabetics (3.7 (4.4) days). Data related to stroke type, site, and size were derived only from the 152 of 176 patients who had CT scans. Second CT scans were performed in $10 \%$ of patients. Five diagnostic stroke types were used: cortical infarction; lacunar infarction; striatocapsular infarction; brainstem or cerebellar haemorrhage; and haemorrhage.

Stroke types were diagnosed ${ }^{20}$ with accepted clinical criteria and confirmed with CT scanning, where possible, demonstrating an acute infarct or haemorrhage at a site concordant with the clinical stroke syndrome. A diagnosis of cortical infarction required clinical evidence of cortical involvement, such as aphasia, apraxia, agnosia, or cortical sensory loss, with or without evidence of acute cortical infarction on CT scanning but with no evidence of acute haemorrhage. A diagnosis of lacunar infarction required the presence of a classical lacunar syndrome, ${ }^{20}$ including pure motor hemiparesis, pure sensory stroke, sensorimotor stroke, ataxic hemiparesis, or the dysarthria clumsy hand syndrome, with no clinical or CT evidence of cortical involvement or cerebral haemorrhage and with or without confirmatory CT scan finding of lacunar infarction, defined as a small deep infarct in the territory of a single penetrating artery, maximal diameter less than $1.5 \mathrm{~cm}$. The diagnosis of striatocapsular infarction relied on the CT scan finding of a comma-shaped subcortical infarct due to occlusion of multiple penetrating arteries, diameter greater than $3 \mathrm{~cm}$. The diagnosis of brainstem or cerebellar infarction was based on clinical evidence of acute infarction affect- ing the vertebrobasilar arterial territory and on the absence of posterior fossa haemorrhage on CT scan. The diagnosis of cerebral haemorrhage required $\mathrm{CT}$ scan confirmation of an acute haemorrhage relevant to the patient's clinical presentation.

The CT scans were interpreted by a neuroradiologist (BT) who was blinded to the clinical data. All lesions were documented, including the presence or absence of ischaemic white matter changes, so-called leukoaraiosis. ${ }^{22}$ Lesions were graded according to their type and size as previously reported. ${ }^{23}$ With this protocol ${ }^{23}$ ischaemic lesions were classified into three groups according to size: not visualised or small (no lesion or one with a maximum diameter of $5 \mathrm{~mm}$ visible in not more than two adjacent slices); medium (intermediate between small and large); and large (involving at least one complete vascular territory). Cerebral haemorrhage was also subdivided into three groups: small ( $<5 \mathrm{~mm}$ in diameter in no more than two adjacent slices); medium; and large (10 mm diameter in at least two adjacent slices). Overall $31 \%$ of the patients had carotid evaluation by digital subtraction angiography and $6 \%$ by duplex doppler ultrasonography. The number of patients in each group was too small to permit meaningful analysis according to stroke pathogenesis, in particular thrombotic $v$ embolic cortical infarction.

To evaluate stroke severity and outcome we assessed neurological deficits on admission and documented the in hospital mortality. Stroke severity was calculated for each patient with a neurological index (see appendix 1) based on the Toronto stroke scoring system. ${ }^{24}$ This is a clinical stroke disability scale whereby neurological deficits are weighted so as not to equate neurological abnormalities of differing severity. A good correlation has been found between clinical grades of global stroke severity (mild, moderate, or severe) and this weighted scoring system. ${ }^{24}$ A weighted numerical score (0-3 or $0-5)$ is assigned to each type of neurological deficit (conscious level, higher cortical function, visual system, bulbar function, motor function, sensory system, coordination), the scores are summed, and the total score is expressed as a percentage of the possible maximum score. An item is left blank when by virtue of the patient's condition it cannot be evaluated. In this situation the index is a percentage of the possible maximum score, including only those items evaluated. With this system a higher neurological index implies a more severe neurological deficit.

STATISTICAL ANALYSIS

Patients with stress hyperglycaemia, newly diagnosed diabetes, and non-diabetics were compared with the euglycaemic, non-diabetic patients on a number of measures. For binary outcomes (that is, presence or absence of a characteristic) comparisons were made by $2 \times$ 2 contingency table analyses with the $\chi^{2}$ statistic or Fisher's exact test (if any expected cell count was less than 5). Continuous measures were compared by $t$ tests and for measures 
with skewed distributions confirmed by a $t$ test of the $\log$ transformed measure. Multivariate analyses were carried out by multiple regression (admission neurological index) or logistic regression (mortality) with the generalised linear interactive modelling (GLIM) statistical package. ${ }^{25}$ Nominal $p$ values are quoted. These must be interpreted with caution due to the multiple comparison nature of the analysis.

A one-tailed $t$ test was used to examine the hypothesis that there is an increase in adverse outcomes with increasing blood glucose in the euglycaemic group because there is a priori evidence to suggest the directional aspect of this non-null hypothesis. Odds ratios with $95 \%$ confidence intervals were used to examine associations in stroke type, lesion site, lesion size, and stroke outcome between the combined hyperglycaemic and diabetic groups (stress hyperglycaemia, newly diagnosed diabetes, and known diabetics) and the euglycaemic, non-diabetic patients. The pattern of survival in each of the four patient groups was assessed with Kaplan-Meier estimates of survival probability, with the Mantel-Cox (logrank) test used to examine possible differences between the four groups.

\section{Results}

The study included 176 patients, of which 116 were euglycaemic with no history of diabetes, including 79 patients with a normal HbAlc and 37 patients with a marginally elevated HbAlc (8.1-9.8\%). There were 10 patients with stress hyperglycaemia, 20 new diabetics, and 30 known diabetics. There was no difference in the proportion of patients who had had previous strokes in the four groups (euglycaemic, non-diabetic patients $16 / 116$; stress hyperglycaemia two of 10 ; newly diagnosed diabetics three of 20 ; known diabetics four of
30 patients).

The demographic characteristics, risk factor distribution, and biochemical data for patients in each group are shown in table 1. Of the known diabetics, 10 had been treated with diet alone and 14 with oral hypoglycaemics, four were insulin dependent, and in two patients, treatment was unknown. All baseline data and results for the diabetic and hyperglycaemic patients were compared with the euglycaemic, non-diabetic patients by univariate and multivariate analysis. Any statistical difference between the groups in terms of stroke outcome could therefore be reliably attributed to their classification according to criteria relating to diabetic state.

Mean (SD) admission glucose concentration was not significantly different between patients with stress hyperglycaemia $(9.7(2.5) \mathrm{mmol} / \mathrm{l})$, newly diagnosed diabetics $(10 \cdot 4(2 \cdot 8) \mathrm{mmol} / \mathrm{l})$, and known diabetics $(11.2(5 \cdot 8) \mathrm{mmol} / \mathrm{l})$ but was significantly higher in each group when compared with the euglycaemic, non-diabetic patients $(5.7(1.0) \mathrm{mmol} / \mathrm{l}, \mathrm{p}<0.001)$. The euglycaemic, non-diabetic patients with a normal $\mathrm{HbAlc}$ concentration had a mean (SD) glucose concentration of $5.6(0.9) \mathrm{mmol} / \mathrm{l}$, not significantly different from euglycaemic, nondiabetic patients with a mildly elevated $\mathrm{HbAlc}$ concentration and mean glucose concentration of $5 \cdot 9(1 \cdot 1) \mathrm{mmol} / \mathrm{l}$.

\section{STROKE TYPE}

There was a marginally greater proportion of patients with a diagnosis of cortical infarction in newly diagnosed diabetics when compared with the euglycaemic, non-diabetic patients $\chi^{2}$ $=4.19, \mathrm{p}<0.05)$. Otherwise, no difference was found in the type of stroke between the four groups (table 2). By using odds ratios, the combined hyperglycaemic and diabetic groups were compared with the euglycaemic, non-

Table 1 Demographic characteristics and data on risk factors for 176 patients presenting with stroke

\begin{tabular}{|c|c|c|c|c|}
\hline & $\begin{array}{l}\text { Euglycaemic } \\
\text { no history } \\
\text { of diabetes } \\
(n=116)\end{array}$ & $\begin{array}{l}\text { Stress } \\
\text { hyperglycaemia } \\
(n=10)\end{array}$ & $\begin{array}{l}\text { New } \\
\text { diabetics } \\
(n=20)\end{array}$ & $\begin{array}{l}\text { Known } \\
\text { diabetics } \\
(n=30)\end{array}$ \\
\hline $\begin{array}{l}\text { Mean (2SD) age (years) } \\
\text { Men, women } \\
\text { No with hypertension } \\
\text { No who smoked } \\
\text { Mean (2SD) cholesterol (mmol/l) } \\
\text { Mean (2SD) triglyceride (mmol/l) } \\
\text { Mean (2SD) packed cell volume (\%) } \\
\text { Mean (2SD) creatinine (mmol/l) } \\
\text { Mean (2SD) urea (mmol/l) } \\
\text { Mean (2SD) fibrinogen }(\mathrm{g} / \mathrm{l})\end{array}$ & $\begin{array}{l}68(27) \\
63,53 \\
64 \\
61 \\
6 \cdot 4(3 \cdot 1) \\
1 \cdot 4(1 \cdot 8) \\
42(12) \\
0 \cdot 11(0 \cdot 05) \\
7 \cdot 0(5 \cdot 9) \\
3 \cdot 6(1 \cdot 9)\end{array}$ & $\begin{array}{l}67(19) \\
8,2 \\
7 \\
1 \\
6 \cdot 1(2 \cdot 5) \\
0 \cdot 9(0 \cdot 8) \\
44(9) \\
0 \cdot 11(0 \cdot 04) \\
6 \cdot 6(4 \cdot 8) \\
3 \cdot 4(1 \cdot 8)\end{array}$ & $\begin{array}{l}76(19) \\
10,10 \\
7 \\
5 \\
6 \cdot 2(2 \cdot 9) \\
1 \cdot 3(1 \cdot 1) \\
41(13) \\
0 \cdot 14(0 \cdot 12) \\
9 \cdot 8(11 \cdot 1) \\
4 \cdot 1(2 \cdot 4)\end{array}$ & $\begin{array}{l}69(27) \\
14,16 \\
23 \\
9 \\
6 \cdot 4(2 \cdot 7) \\
1 \cdot 8(2 \cdot 7) \\
41(14) \\
0 \cdot 11(0 \cdot 06) \\
7 \cdot 2(0 \cdot 1) \\
4 \cdot 1(2 \cdot 5)\end{array}$ \\
\hline
\end{tabular}

Table 2 Types of stroke in 152 patients who had CT scans

\begin{tabular}{|c|c|c|c|c|c|}
\hline Pathology & $\begin{array}{l}\text { Euglycaemic } \\
\text { no history } \\
\text { of diabetes } \\
(n=100)\end{array}$ & $\begin{array}{l}\text { Stress } \\
\text { hyperglycaemia } \\
(n=7)\end{array}$ & $\begin{array}{l}\text { New } \\
\text { diabetics } \\
(n=18)\end{array}$ & $\begin{array}{l}\text { Known } \\
\text { diabetics } \\
(n=27)\end{array}$ & $\begin{array}{l}\text { Odds } \\
\text { ratio } \\
\text { (confidence interval) }\end{array}$ \\
\hline $\begin{array}{l}\text { Cortical } \\
\text { Lacunar } \\
\text { Striatocapsular } \\
\text { Brainstem/cerebellar } \\
\text { Haemorrhage }\end{array}$ & $\begin{array}{l}46(46 \%) \\
15(15 \%) \\
5(5 \%) \\
13(13 \%) \\
21(21 \%)\end{array}$ & $\begin{array}{l}2(29 \%) \\
1(13 \%) \\
0 \\
2(29 \%) \\
2(29 \%)\end{array}$ & $\begin{array}{l}13(72 \%) \dagger \\
2(11 \%) \\
0 \\
2(11 \%) \\
1(6 \%)\end{array}$ & $\begin{array}{l}16(59 \%) \\
1(4 \%) \\
3(11 \%) \\
2(7 \%) \\
5(19 \%)\end{array}$ & $\begin{array}{l}0.58(0.29 \text { to } 1.15) \\
2.12(0.65 \text { to } 6.9) \\
0.86(0.19 \text { to } 3.9) \\
1.15(0.40 \text { to } 3.3) \\
1.46(0.59 \text { to } 3.6)\end{array}$ \\
\hline
\end{tabular}

*No significant differences in stroke type found in combined hyperglycaemic and diabetic groups compared with the euglycaemic, non-diabetic patients. Odds ratio $>1$ indicates stroke type more common in combined hyperglycaemic and diabetic groups; odds non-diabetic patients. Odds ratio $>1$ indicates stroke type more common in combined hyperglycaemic and diabetic groups; odds
ratio $<1$ indicates stroke type less common in combined hyperglycaemic and diabetic groups; odds ratio $=1$ means equals ratio < I indicates stroke type less common in combined hyperglycaemic and diabetic groups; odds ratio $t x^{2}=4.19, p<0.05$ (new diabetics compared with euglycaemic, non-diabetic patients). 
Table 3 Site of lesion in 152 patients with stroke who had CT scan

\begin{tabular}{|c|c|c|c|c|c|}
\hline $\begin{array}{l}\text { Site of lesion } \\
\text { by } C T \text { scan }\end{array}$ & $\begin{array}{l}\text { Euglycaemic } \\
\text { no history } \\
\text { of diabetes } \\
(n=100)\end{array}$ & $\begin{array}{l}\text { Stress } \\
\text { hyperglycaemia } \\
(n=7)\end{array}$ & $\begin{array}{l}\text { New } \\
\text { diabetics } \\
(n=18)\end{array}$ & $\begin{array}{l}\text { Known } \\
\text { diabetics } \\
(n=27)\end{array}$ & $\begin{array}{l}\text { Odds } \\
\text { ratio } \\
\text { (confidence interval) }\end{array}$ \\
\hline $\begin{array}{l}\text { Relevant lacunes } \\
\text { Incidental lacunes } \\
\text { White matter ischaemia } \\
\text { Relevant cortical } \\
\text { Incidental cortical } \\
\text { Striatocapsular } \\
\text { Haemorrhage } \\
\text { Brainstem/cerebellar }\end{array}$ & $\begin{array}{l}11(11 \%) \\
28(28 \%) \\
29(29 \%) \\
33(33 \%) \\
10(10 \%) \\
6(6 \%) \\
21(21 \%) \\
4(4 \%)\end{array}$ & $\begin{array}{l}0 \\
1(14 \%) \\
1(14 \%) \\
2(29 \%) \\
1(14 \%) \\
0 \\
2(29 \%) \\
1(14 \%)\end{array}$ & $\begin{array}{l}1(6 \%) \\
6(33 \%) \\
9(50 \%) \\
5(28 \%) \\
1(5 \%) \\
0 \\
1(6 \%) \\
1(6 \%)\end{array}$ & $\begin{array}{l}1(4 \%) \\
5(19 \%) \\
6(22 \%) \\
8(30 \%) \\
0 \\
3(11 \%) \\
5(19 \%) \\
0\end{array}$ & $\begin{array}{l}3.09(0.64 \text { to } 15.0) \\
1.30(0.59 \text { to } 2.9) \\
0.92(0.44 \text { to } 1.9) \\
1.22(0.58 \text { to } 2.6) \\
2.78(0.57 \text { to } 13.6) \\
1.04(0.24 \text { to } 4.5) \\
1.46(0.59 \text { to } 3.6) \\
1.04(0.18 \text { to } 6.1)\end{array}$ \\
\hline
\end{tabular}

* No significant differences in lesion site (both symptomatic and incidental) found in combined hyperglycaemic and diabetic groups compared with euglycaemic, non-diabetic patients.

Table 4 Size of lesion in 152 patients with stroke who had CT scan

\begin{tabular}{llllll}
\hline Site of lesion & $\begin{array}{l}\text { Euglycaemic } \\
\text { no history } \\
\text { of diabetes } \\
(n=100)\end{array}$ & $\begin{array}{l}\text { Stress } \\
\text { hyperglycaemia } \\
(n=7)\end{array}$ & $\begin{array}{l}\text { New } \\
\text { diabetics } \\
(n=18)\end{array}$ & $\begin{array}{l}\text { Known } \\
\text { diabetics } \\
(n=27)\end{array}$ & $\begin{array}{l}\text { Odds } \\
\text { ratio } \\
(\text { confidence interval) }\end{array}$ \\
\hline Absent or small & $38(38 \%)$ & $2(29 \%)$ & $12(67 \%) \dagger$ & $10(37 \%)$ & $0 \cdot 72(0.36$ to $1 \cdot 4)$ \\
Medium & $40(40 \%)$ & $1(14 \%)$ & $2(11 \%)$ & $11(41 \%)$ & $1 \cdot 81(0.86$ to $3 \cdot 8)$ \\
Large & $22(22 \%)$ & $4(57 \%) \ddagger$ & $4(22 \%)$ & $6(22 \%)$ & $0.77(0.35$ to $1 \cdot 7)$
\end{tabular}

^No significant differences in lesion size found in combined hyperglycaemic and diabetic groups compared with euglycaemic, non-

diabetic patients.
$+\chi^{2}=5 \cdot 13, p<0.05$

$+\chi^{2}=5 \cdot 13, p<0.05$
$\mp \chi^{2}=4.39, p<0.05$

diabetic patients and no difference was found in the proportion of stroke types between these two groups.

CT SCAN FINDINGS

Lesion site-No significant difference was found between the four groups with regard to site of symptomatic and asymptomatic lesions on CT scan. In particular, there was no difference in the incidence of asymptomatic lacunes or leukoaraiosis (table 3).

Lesion size - Compared with euglycaemic, nondiabetic patients there was a marginally greater number of large lesions (infarction or haemorrhage) in patients with stress hyperglycaemia $\left(\chi^{2}=4.39, p<0.05\right)$. In the newly diagnosed diabetics there was a larger number of patients with either a small lesion or normal CT scan $\left(\chi^{2}=5 \cdot 13, p<0.05\right.$; table 4$)$. By using odds ratios to compare lesion size in the combined hyperglycaemic and diabetic groups with the euglycaemic, non-diabetic patients, however, no significant differences were found between these groups.

NEUROLOGICAL OUTCOME (TABLE 5)

Stroke severity-Compared with the euglycaemic, non-diabetic patients stroke severity, as measured by the admission neurological index, was significantly worse in patients with stress hyperglycaemia $(p<0.001)$ and known diabetics $(p<0.05)$. In known diabetics stroke outcome did not correlate with diabetic control, assessed by the concentration of HbAlc.

Mortality - Was significantly higher in patients with stress hyperglycaemia $(p<0.001)$ and newly-diagnosed diabetics $(p<0.001)$ when compared with the euglycaemic, non-diabetic patients. A trend to higher mortality was seen in patients with known diabetes, but this did not reach significance $(0.05<\mathrm{p}<0.10)$. Combining the newly and previously diagnosed diabetic groups, the mortality was significantly greater than for the euglycaemic, non-diabetic subjects $(p<0.05)$. When patients from each of the four groups were pooled the mean (SD) admission glucose concentration was significantly higher in patients who died $(8 \cdot 4(5 \cdot 1) \mathrm{mmol} / \mathrm{l})$ when compared with survivors $(6.3(3.6) \mathrm{mmol} / \mathrm{l} ; \mathrm{p}$ $<0.05)$. Within the hyperglycaemic and diabetic patients, however, there was no relation between glucose concentration and mortality. By using odds ratios, the proportion of patients who died in the combined hyperglycaemic and

Table 5 Neurological outcome and mortality in 176 patients with stroke

\begin{tabular}{|c|c|c|c|c|c|}
\hline & \multicolumn{2}{|c|}{ Euglycaemic patients } & \multirow[b]{2}{*}{$\begin{array}{l}\text { Stress } \\
\text { hyperglycaemia } \\
(n=10)\end{array}$} & \multirow[b]{2}{*}{$\begin{array}{l}\text { New } \\
\text { diabetics } \\
(n=20)\end{array}$} & \multirow[b]{2}{*}{$\begin{array}{l}\text { Known } \\
\text { diabetics } \\
(n=30)\end{array}$} \\
\hline & $\begin{array}{l}\text { Normal } \\
\text { HbA1c } \\
(n=79)\end{array}$ & $\begin{array}{l}\text { Elevated } \\
\text { HbA1c } \\
(n=37)\end{array}$ & & & \\
\hline $\begin{array}{l}\text { Mean (SD) neurological index } \\
\text { on admission } \\
\text { Mortality \% }\end{array}$ & $\begin{array}{l}24(20) \\
11 \%\end{array}$ & $\begin{array}{l}25(20) \\
16 \%\end{array}$ & $\begin{array}{l}53(50)^{\star} \\
80 \%^{\star}\end{array}$ & $\begin{array}{l}29(43) \\
45 \% \star\end{array}$ & $\begin{array}{l}33(40) \dagger \\
25 \% \ddagger\end{array}$ \\
\hline
\end{tabular}




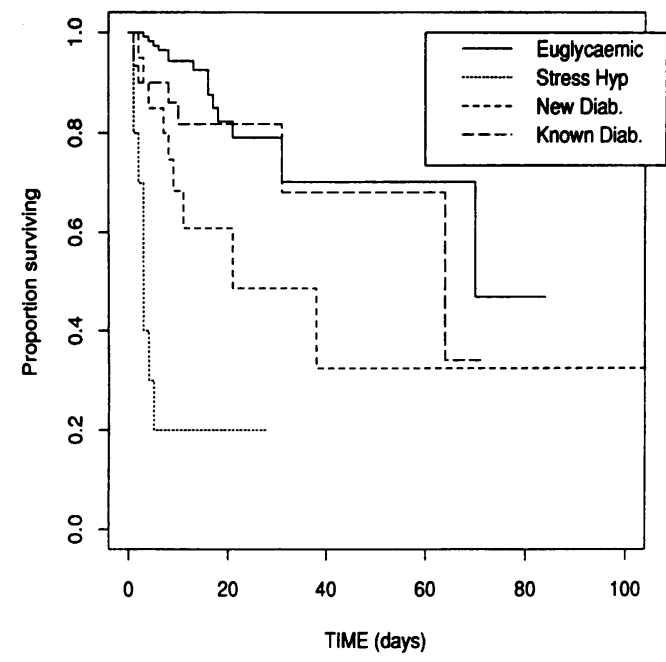

Figure Kaplan-Meier estimates of survival according to patient type. All survival times were censored at time of discharge if this preceded death. One patient in the new diabetic group was discharged at 18 days (point not shown on the graph). Log-Rank test for group differences: $\chi^{2}=58 \cdot 7,3$ d.f. $(p<0.001)$.

diabetic groups was significantly higher than in the euglycaemic, non-diabetic patients (odds ratio ( $95 \%$ confidence interval) $4.5(2.1$ to 10.0). Patients with cerebral haemorrhage were then excluded from this mortality analysis and a significant difference was still evident, with higher mortality in the hyperglycaemic and diabetic patients (3.8 (1.6 to 8.8). Analysis of survival time after the stroke with KaplanMeier curves (figure) suggested that survival among the new diabetics was intermediate between that of the stress hyperglycaemia cases (high mortality) and the euglycaemic and known diabetic groups (lower mortality). The significantly greater mortality in patients with stress hyperglycaemia compared with nondiabetics was due to an increase in early mortality, all deaths in this group occurring within one week after stroke. Although mortality increased with age $(p<0.05)$ the statistical inferences on the differences in mortality by patient groups were not altered by adjustment for age, stroke type, or stroke size in a multiple linear logistic model. In patients who died it was apparent that the excess mortality in the group with stress hyperglycaemia was due to the neurological effects of the large stroke (table 6).

Glucose, stroke severity, and mortality in euglycaemic, non-diabetic patients-In the 116 eugly- caemic, non-diabetic patients mortality in the 40 patients with glucose $>6 \mathrm{mmol} / \mathrm{l}$ was $27.8 \%$, higher than the $5.6 \%$ in the 76 patients with glucose $\leqslant 6 \mathrm{mmol} / \mathrm{l}(\mathrm{p}<0.01)$. By multiple linear logistic regression mortality increased independently with glucose $(p<$ $0.05)$ and age $(p<0.05), 1 \mathrm{mmol} / 1$ of glucose being equivalent to 10 years of age. The observed mortality in the subset of euglycaemic patients with glucose in the range $6 \cdot 0-7 \cdot 8 \mathrm{mmol} / 1$ did not exceed the mortality in the other three groups. There was also an association between mortality and $\mathrm{HbAlc}$ concentration in this group after adjusting for age ( $p=0.05$ ), but this did not confound the significant relation between blood glucose and mortality. The mean admission neurological index was also strongly dependent on glucose, rising by 8 (SD 2) units for every $\mathrm{mmol} / \mathrm{l}$ ( $\mathrm{p}<$ 0.001 ) and independent of age and HbAlc. When we compared the euglycaemic, nondiabetic patients with normal and mildly elevated $\mathrm{HbAlc}$ there was no difference in either the admission neurological index (24 (20) $v 25$ (20)) or mortality $(8 / 76,11 \% v 6 / 37,16 \%)$.

\section{Discussion}

We have shown a high prevalence of both known diabetes $(17.0 \%)$ and newly diagnosed diabetes $(11.4 \%)$ in patients presenting with stroke to an acute hospital stroke unit. These figures are significantly higher than the prevalence figures in the comparable age group in the general population of Busselton (Western Australia) with a prevalence of $3.4 \%$ known diabetics and $3.1 \%$ newly diagnosed diabetics. ${ }^{26}$ Previous reports of the prevalence of diabetes in acute stroke have provided widely varying results, which may reflect different methods of measurement of HbAlc. ${ }^{56}$ Riddle and $\mathrm{Hart}^{6}$ measured $\mathrm{HbAlc}$ in patients with recent stroke or transient ischaemic attacks and found that $42 \%$ of such patients had abnormal concentrations. A colorimetric assay method was used, however, which does not remove labile adducts, and therefore the concentrations of HbAlc may have been artefactually high. In a study by Oppenheimer et $a l^{5}$ the concentration of $\mathrm{HbAlc}$ free of labile adducts was determined with an isoelectric focussing technique. They found only a $6 \%$ prevalence of undiagnosed diabetes in patients with acute stroke.

Table 6 Cause of death in 38 patients with stroke who died

\begin{tabular}{|c|c|c|c|c|}
\hline & $\begin{array}{l}\text { Euglycaemic } \\
\text { no history } \\
\text { of diabetes }\end{array}$ & $\begin{array}{l}\text { Stress } \\
\text { hyperglycaemia }\end{array}$ & $\begin{array}{l}\text { New } \\
\text { diabetics }\end{array}$ & $\begin{array}{l}\text { Known } \\
\text { diabetics }\end{array}$ \\
\hline $\begin{array}{l}\text { Neurological } \\
\text { Mass effect cerebral oedema } \\
\text { Mass effect haematoma } \\
\text { Primary destruction vital medullary centres } \\
\text { Other }\end{array}$ & $\begin{array}{l}4 \\
3 \\
2 \\
1\end{array}$ & $\begin{array}{l}2 \\
4 \\
2\end{array}$ & $\begin{array}{l}1 \\
1 \\
1 \\
1\end{array}$ & $\begin{array}{l}3 \\
1 \\
1\end{array}$ \\
\hline $\begin{array}{l}\text { Systemic factors } \\
\text { Sepsis } \\
\text { AMI/cardiac } \\
\text { Pulmonary embolism } \\
\text { Other }\end{array}$ & 2 & & $\begin{array}{l}3 \\
1\end{array}$ & 1 \\
\hline $\begin{array}{l}\text { Sudden death of unknown cause } \\
\text { Unrelated to stroke }\end{array}$ & 1 & & 1 & 1 \\
\hline
\end{tabular}


We used two criteria for the diagnosis of diabetes; an elevated fasting plasma glucose $>$ $7 \cdot 8 \mathrm{mmol} / 1$ and $\mathrm{HbAlc}>8.0 \%$. Some patients who had a normal fasting plasma glucose and no known history of diabetes had a marginally raised $\mathrm{HbAlc}(8 \cdot 1-9 \cdot 8 \%)$. The mean blood glucose concentration for this subgroup was not significantly different to the subjects with a normal $\mathrm{HbAlc}$, and no significant difference in mortality was detected between the two subgroups. They were therefore treated as a combined group (euglycaemic, non-diabetic patients for the other analyses).

Our finding of $11.4 \%$ prevalence of newly diagnosed diabetes is probably an accurate reflection of the prevalence of undiagnosed diabetes in an acute hospital stroke population, although geographical differences may occur. For example, Woo et al ${ }^{19}$ reported a lower $5.3 \%$ prevalence in a regional general hospital in Hong Kong. Davis et $a l^{27}$ reported that there is a short median time between the onset of diabetes and stroke and therefore a high incidence of newly-diagnosed diabetes in acute stroke could be expected.Although the number of patients in the hyperglycaemic groups were fairly small, statistical analysis indicated that stroke severity was significantly worse in patients with either stress hyperglycaemia or known diabetes when compared with concurrent non-diabetic patients with similar demographic characteristics and risk factors. In addition, there was a higher mortality in patients with stress hyperglycaemia and in the combined diabetic groups. Even in the euglycaemic, non-diabetic group there was an independent effect of glucose on mortality with a substantial difference in outcome between patients with a glucose concentration above or below $6 \mathrm{mmol} / \mathrm{l}$. This finding supports that of Mohr et $a l^{18}$ who analysed the relation between admission glucose concentration and stroke mortality, based on the NINCDS data bank, and found that the additional effect of hyperglycaemia was small compared with the increased mortality observed in patients in the upper euglycaemic range.

Our laboratory uses the WHO criterion for fasting glucose ( $>7.8 \mathrm{mmol} / \mathrm{l}$ ), and this glucose concentration was also used by Gray et $a l^{17}$ and Woo et $a l^{19}$ to distinguish nondiabetic subjects with euglycaemia or stress hyperglycaemia. A proportion of the patients with fasting blood glucose concentrations in the range $6 \cdot 1-7 \cdot 8 \mathrm{mmol} / \mathrm{l}$, however, would probably have impaired glucose tolerance on formal testing and may be regarded as having a pre-diabetic state. Several studies have shown a greater mortality for intracerebral haemorrhage $v$ cerebral infarction, ${ }^{28}$ and the greater proportion of the former in patients with stress hyperglycaemia may account form some of the mortality differences. An increased mortality in the hyperglycaemic and diabetic patients, however, was evident even after patients with cerebral haemorrhage had been excluded from the analysis. Stress hyperglycaemia is also reported to be more common and more severe in patients with intracerebral haemorrhage compared with ischaemic stroke, ${ }^{29}$ and there is a correlation between hyperglycaemia in haemorrhagic stroke and poor prognosis. ${ }^{1829}$

As indicated in the methods, statistical tests were applied to multiple analyses and therefore a proportion of nominally significant $p$ values would be anticipated by chance alone. Rather than quoting only highly significant values (for example, $\mathrm{p}<0.001$ ) we have instead indicated associations which in themselves are unlikely to be attributed to chance and can therefore be the subject of assessment by independent studies. The numbers in the groups are small, however, and hence may be subject to type 2 error. Because of the small numbers we combined the hyperglycaemic and diabetic groups and used odds ratios with $95 \%$ confidence intervals to compare stroke type, site, size, and outcome with the euglycaemic, non-diabetic patients.

Animal experiments with controlled degrees of cerebral ischaemia have shown that elevated blood-brain glucose concentrations greatly enhance the extent and degree of subsequent brain damage. ${ }^{11-133031} \mathrm{~A}$ retrospective study by Pulsinelli et al $^{14}$ confirmed that patients with diabetes and hyperglycaemia had a worse neurological outcome after ischaemic stroke than non-diabetic patients. Cox and Lorains ${ }^{32}$ measured blood glucose and HbAlc in 81 patients presenting with acute hemiplegic stroke. They concluded that stress hyperglycaemia was associated with a worse prognosis than pre-existing diabetes. Oppenheimer and Hoffbrand ${ }^{5}$ found a greater early mortality in diabetic compared with non-diabetic patients.

Our findings support the conclusions of Gray et al, ${ }^{17}$ who also used both blood glucose and $\mathrm{HbAlc}$ measurements to differentiate previously unrecognised diabetes and hyperglycaemia in acute stroke patients. They found a raised mortality at four weeks in patients with elevated blood glucose, irrespective of $\mathrm{HbAlc}$ values, but did not examine the proportion of infarcts and haemorrhages or distinguish the proportion of cortical versus lacunar infarcts. Woo et $a l^{19}$ used the same four glucose tolerance categories as we did to analyse the effects of hyperglycaemia and diabetes on stroke outcome and concluded that the association between glucose concentration and outcome was related to stress and stroke severity rather than a direct harmful effect of glucose on damaged neurons. In contrast to their findings, we found a worse outcome in both diabetic patients and those with stress hyperglycaemia.

Although we mainly performed early CT scans in our study, we found a marginally greater number of large lesions (infarction or haemorrhage) in patients with stress hyperglycaemia compared with the euglycaemic, non-diabetic patients, but no difference in lesion size was found when the hyperglycaemic and diabetic patients were combined and then compared with the euglycaemic, non-diabetic subjects. In acute cerebral infarction, CT scans are often normal, and measurement of lesion size by CT scan should ideally be performed at 
7-10 days. ${ }^{33}$ Patients in our study with large infarcts on clinical criteria might therefore have shown no abnormality or only a small lesion on an early CT scan. None the less, the poor outcome stress hyperglycaemic group in fact had significantly earlier CT scans than the euglycaemic, non-diabetic patients.

The significance of hyperglycaemia in the context of acute stroke and its relation to stroke outcome remains complex. No conclusions about cause can be made at this stage. Considerable evidence indicates that hyperglycaemia intensifies brain injury secondary to experimental cerebral ischaemia. ${ }^{11314}$ On the other hand, size and severity of cerebral injury may be relevant in the causation of stress hyperglycaemia and large strokes may lead to hyperglycaemia and determine a worse prognosis. ${ }^{19293234}$ Both fasting glucose and $\mathrm{HbAlc}$ should be estimated in clinical studies to enable differentiation between patients with stress hyperglycaemia and those with unrecognised diabetes.

We could not confirm the postulated association between diabetes and lacunar infarction. ${ }^{78}$ We found no significant differences in the type or site of stroke between the four groups, although our numbers were small and might be subject to type 2 error. Independent analysis of the CT scans, looking for evidence of asymptomatic small vessel disease, revealed no difference between diabetics and nondiabetics. We therefore concluded that the worse neurological outcome in patients with either stress hyperglycaemia or diabetes could not be related to lesion site, specifically cortical versus lacunar infarction.

Various mechanisms have been implicated to explain the higher incidence of stroke and worse prognosis in diabetic and hyperglycaemic patients. These include an alteration of post-ischaemic cerebral blood flow related to impaired cerebral autoregulation, ${ }^{35}$ a hyperosmolar effect of blood glucose, ${ }^{11}$ and interference with collateral blood flow in the periischaemic zone due to proliferative angiopathy of small cerebral blood vessels. ${ }^{36}$ Other factors identified in diabetic patients that might exacerbate ongoing cerebral ischaemia are an increase in whole blood or plasma viscosity, ${ }^{37}$ reduced deformability of erythrocytes, ${ }^{38}$ and increased adhesion of erythrocytes to endothelial cells. ${ }^{39}$

Pulsinelli et al, ${ }^{11}$ using a four vessel occlusion rat model, showed that glucose given before the onset of cerebral ischaemia was followed by severe brain injury, suggesting that the level of pre-ischaemic brain carbohydrate stores influences both the severity and histology of subsequent brain damage. The concentration of brain carbohydrate is a major factor in determining whether an ischaemic insult causes cerebral infarction with a greater threat to tissue or results in a more restricted injury limited to ischaemic neuronal damage. Equal degrees of ischaemia accompanied by lower tissue lactate values produce only selective neuronal damage in predictably vulnerable areas; astrocytes and endothelia are spared and extracellular or progressive post-ischaemic cer- ebral oedema fails to develop. ${ }^{40}$ Pulsinelli et $\mathrm{al}^{11}$ concluded that excessive accumulation of lactic acid resulting from anaerobic glycolysis by an ischaemic brain is the most likely explanation of the enhanced brain damage in hyperglycaemic animals.

Our study indicates that either pre-existing diabetes, known or newly diagnosed, or stress hyperglycaemia are conditions associated with a worse prognosis after stroke. This may be due to biochemical factors ${ }^{40}$ rather than stroke type or site and the mechanisms may be different in these two situations. ${ }^{41}$ Even in euglycaemic patients without known diabetes the admission glucose concentration correlates strongly with stroke outcome. While there is no proof of a causal relation between hyperglycaemia and adverse stroke prognosis, Mohr ${ }^{18}$ and other investigators ${ }^{42-44}$ have suggested that hypoglycaemia might indeed confer some protection against ischaemia. Animal studies ${ }^{42-44}$ have shown a beneficial effect of insulin in acute cerebral and spinal cord ischaemia, particularly with reduction of glucose concentrations to the low euglycaemic to mildly hypoglycaemic range. There have, however, been no reported human studies to date. A randomised controlled trial is needed to study glucose management in acute stroke. Such a trial could involve randomisation of patients with elevated blood glucose to either a treatment protocol (for example, standard treatment plus glucose reduction to achieve a target of $6 \mathrm{mmol} / \mathrm{l}) v$ standard treatment alone.

This study was presented in part at the 14th International Joint Conference on Stroke and Cerebral Circulation, San Antonio, Texas, in February 1989. The work was supported by a grant from the Higginbottom Neuroscience Research Institute.

1 Garcia MJ, McNamara PM, Gordon T, Kannell WB. Morbidity and mortality in diabetics in the Framingham population. Diabetes 1974;23:105-11.

2 Toyama K, Nerishi S, Kawamoto S, Kato H, Miyake S, Nagataki S. Risk factors of cerebro-cardiovascular disorders in mild diabetes. Tohoku $\mathcal{J}$ Exp Med 1983;141(suppl);535-40.

3 Kannell WB, McGee DL. Diabetes and cardiovascular disease. The Framingham Study. $\mathcal{F} A M A$ 1979;241: 2035-8.

4 Wolf P, Kannell WB. Controllable risk factors for stroke: preventative implications of trends in stroke mortality. In: and TIA's. California: Addison-Wesley, 1982:25-61.

5 Oppenheimer SM, Hoffbrand BI, Oswald GA, Yudkin JS. Diabetes mellitus and early mortality from stroke. BMF 1985;291:1014.

6 Riddle Mc, Hart J. Hyperglycemia, recognised and unrecognised, as a risk factor for stroke and transient ischemic

7 Kane WC, Aronson SM. Frequency and topographic distribution of intracranial vascular diseases in diabetic patients. A necropsy survey (abstract). Am $\mathcal{f}$ Pathol 1968;52:71a.

8 Peress NS, Kane WC, Aronson SM. Central nervous system findings in a tenth decade autopsy population. Prog Brain Res 1973;40:473-83.

9 Mohr JP, Caplan LR, Melski JW, et al. The Harvard Cooperative stroke registry: a prospective registry. Neurology 1978;28:754-62.

10 Gross CR, Kase CS, Mohr JP, Cunningham SC, Baker WE. Stroke in South Alabama: incidence and diagnostic features $-a$ population based study. Stroke 1984; 15:249-55.

11 Pulsinelli WA, Waldman S, Rawlinson D, Plum F. Moderate hyperglycaemia augments ischemic brain damage: a neuropathologic study in the rat. Neurology 1982; neuropathologi

12 Myers RE, Yamaguchi S. Nervous system effects of cardiac arrest in monkeys. Arch Neurol 1977;34:65-74.

13 Siemkowicz E, Hansen A. Clinical restitution following cerebral ischemia in hypo-, normo- and hyperglycemic cerebral ischemia in hypo-, normo-

14 Pulsinelli WA, Levy DE, Sigsbee B, Scherer P, Plum F Increased damage after ischemic stroke in patients with hyperglycemia with or without established diabetes mellitus. Am ₹ Med 1983;74:540-4. 
15 Fuller JH, Shipley MJ, Rose G, Jarrett RJ, Keen H. Mortality from coronary heart disease and stroke in relation to degree of glycaemia: the Whitehall study. $B M F$ 1983;287:867-70.

16 Asplund K, Hagg E, Helmers C, Lithner F, Strand T, Webster PO. The natural history of stroke in diabetic patients. Acta Med Scand 1980;207:417-24.

17 Gray CS, Taylor R, French JM, et al. The prognostic value of stress hyperglycaemia and previous unrecognised diabetes stress hyperglycaemia and previous unrecognised diat

$18 \mathrm{Mohr}$ JP, Rubenstein L, Edelstein SZ, et al. Approaches to pathophysiology of stroke through the NINCDS data bank. In: Plum F, Pulsinelli W, eds. Cerebrovascula diseases, fourteenth research (Princeton-Williamsburg) conference. New York: Raven Press, 1985:63-8.

19 Woo J, Lam CWK, Kay R, Wong AHY, Teoh R, Nicholls MG. The influence of hyperglycaemia and diabetes mellitus on immediate and 3-month morbidity and mortality after acute stroke. Arch Neurol 1990;47: 1174-7.

20 Whisnant JP, Basford JR, Bernstein EF, et al. Classification of cerebrovascular diseases III. Special report from the National Institute of Neurological Disorders and Stroke. Stroke 1990;21:637-76.

21 WHO Expert Committee on Diabetes Mellitus. Second Report. WHO, Geneva: WHO, 1980: Technical Report Series 646.

22 Hachinski VC, Potter P, Merskey H. Leuko-araiosis. Arch Neurol 1987;44:21-3.

23 Candelise L, Landi G, Orazio EN, Boccardi E. Prognostic significance of hyperglycaemia in acute stroke. Arch Neurol 1985;42:661-3.

24 Hachinski V, Norris JW. In: The Acute Stroke. Philadelphia: FA Davis Co, 1985:16-9.

25 Baker AJ, Nelder JA. The GLIM system, release 3. Oxford: Numerical Algorithms Group, 1978.

26 Glatthaar C, Welborn TA, Stenhouse NS, Garcia-Webb P. Diabetes and impaired glucose tolerance. A prevalence estimate based on the Busselton 1981 Survey. Med $\Im$ Aust 1985;143:436-40.

27 Davis PH, Dambrosia JM, Schoenberg BS, et al. Risk factors for ischemic stroke: a prospective study in Rochester, Minnesota. Ann Neurol 1987;22:319-27.

28 Chambers BR, Norris JW, Shurvell, BL, Hachinski VC. Prognosis of acute stroke. Neurology 1987;37:221-5.

29 Melamed E. Reactive hyperglycemia in patients with acute stroke. $\mathcal{F}$ Neurol Sci 1976;29:267-75.

30 Pulsinelli WA, Waldman S, Sigsbee B, Rawlinson D, Shere P, Plum FF. Experimental hyperglycaemia and diabetes mellitus worsen stroke outcome. Trans Am Neurol Assoc 1980;105:21-4.

31 Siemkowicz E, Gjedde A. Post-ischemic coma in rat: effect of different pre-ischemic blood glucose levels on cerebral metabolic recovery after ischemia. Acta Physiol Scand 1980;110:225-32.

32 Cox NH, Lorains JW. The prognostic value of blood glucose and glycosylated haemoglobin estimation in patients with stroke. Postgrad Med ₹ 1986;62:7-10.

33 Brott T, Marler JR, Olinger CP, et al. Measurements of acute cerebral infarction: lesion size by computed tomography. Stroke 1989;20:871-7.

34 Samanta A, Blandford RL, Burden AC, Castleden CM. Glucose tolerance following strokes in the elderly. $A g$ Glucose tolerance followi

35 Bentsen N, Larsen BO, Lassen NA. Chronically impaired autoregulation of cerebral blood flow in long-term diaautoregulation of cerebral blood

36 Alex M, Bacon EK, Goldenberg S, Blumenthal HT. An autopsy study of cerebrovascular accident in diabetes mellitus. Circulation 1962;25:663-73.

37 Barnes AJ, Locke P, Scudder PR, Dormandy TL Dormandy JA, Slack J. Is hyperviscosity a treatable component of diabetic microcirculatory disease? Lancet 1977;ii:789-91.

38 McMillan DE, Utterback NG, LaPuma J. Reduced erythrocyte deformability in diabetes. Diabetes 1978;27: 895-901.

39 Wautier JL, Paton RC, Wautier MP, et al. Increased adhesion of erythrocytes to endothelial cells in diabetes mellitus and its relation to vascular complications. N Engl 7 Med 1981;305:237-42.

40 Plum $F$. What causes infarction in ischemic brain? The Robert Wartenberg lecture. Neurology 1983;33:222-33.

41 Helgason CM. Blood glucose and stroke. Stroke 1988 ; 19:1049-53.

42 Fukuoka S, Yeh H-S, Mandybur TI, Tew JM Jr. Effect of insulin on acute experimental cerebral ischemia in gerbils. Stroke 1989;20:396-9.

43 LeMay DR, Gehua L, Żelenock GB, D'Alecy LG. Insulin administration protects neurologic function in cerebral ischemia in rats. Stroke 1988;19:1411-9.

44 Robertson CS, Grossman RG. Protection against spinal cord ischemia with insulin-induced hypoglycemia. $\mathcal{f}$ Neurosurg 1987;67:739-44.

Appendix

Stroke severity score

A Conscious level

0 Normal

1 Drowsy, responding to verbal command

2 Purposeful response to painful stimulus

3 Semi-purposeful response to painful stimulus
4 Decerebrate/decorticate response to pain

5 Unresponsive to painful stimulus

B Higher cortical function

a) Dysphasia, dyslexia or dysgraphia

0 Normal

1 Mild communication dysfunction

2 Moderate communication dysfunction

3 Severe communication dysfunction

b) Other cortical signs (including, dyspraxia, hemispatial neglect, agnosia)

0 Absent

1 Minor signs of dysfunction

2 Moderate evidence of dysfunction

3 Marked evidence of dysfunction

C Visual system

a) Visual Fields

0 Normal

1 Incomplete hemianopia/Partial monocular loss

2 Complete hemianopia/Monocular blindness

3 Functional blindness

b) Eye movement abnormality

Hemisphere

0 Normal

1 Gaze palsy

2 Forced deviation

Brainstem

0 Normal

1 Partial defect

2 Complete defect

Nystagmus

0 Absent

1 Eccentric, gaze evoked

2 Primary position

D Bulbar function

0 Normal

1 Mild dysfunction with dysarthria and/or dysphagia

2 Moderate dysfunction with dysarthria and/or dysphagia

3 Severe dysfunction with anarthria and/or aphagia

E Motor function (bilateral signs - score each side) Face

0 Normal

1 Mild weakness occurring on testing

2 Moderate weakness with resting facial asymmetry

3 Severe weakness-paralysis

Arm

0 Normal

1 Mild reduction from normal

2 Movement against gravity

3 Movement gravity eliminated

4 Minimal movement at rest

5 Paralysis

Leg

0 Normal

1 Mild reduction from normal

2 Movement against gravity

3 Movement gravity eliminated

4 Minimal movement at rest

5 Paralysis

F Sensory system

0 Normal

1 Mildly impaired or subjective alteration

2 Moderate sensory loss

3 Marked sensory loss all modalities

G Coordination/ataxia (score only if exceeds degree weakness)

0 Signs absent

1 Mildly impaired with limb ataxia only, gain normal

2 Moderate impairment with gait ataxia, walks unsupported

3 Severe impairment, mobile only with support 